\title{
A iminência de morte em questão: a perspectiva e o manejo clínico de psicólogos da saúde pública
}

\section{The imminence of death in question: the perspective of psychologists and clinical management of public health}

Paula M. Pfeifer ${ }^{1}$, Cláudia M. S. Palma²

\begin{abstract}
RESUMO
Modelo do estudo: trata-se de uma pesquisa qualitativa. Objetivo: qualificar a prática do psicólogo, isto é, como se posiciona e atua frente às questões referentes à morte no contexto institucional. Metodologia: Inicialmente, foi realizado levantamento sobre o número de psicólogos que atuam na rede pública de Santa Maria, constituindo-se uma amostra de doze profissionais. Posteriormente, realizamos entrevistas semi-estruturadas e individuais, com duração de uma hora. As entrevistas gravadas foram transcritas, e em seguida, lidas individualmente, destacando-se as falas que apontavam para o modo de trabalho do psicólogo elaborando-se, a partir da recorrência, categorias de análise, buscando-se articular uma perspectiva grupal. O enfoque teórico utilizado para a análise de dados foi o psicanalítico. Resultados: Os resultados apontaram contradições entre a atuação e o posicionamento referido pelo psicólogo na iminência da morte de um paciente, sobrepondo-se um fazer invadido pela pessoalidade do profissional. Além disso, constatamos o perigo de adotar-se uma prática que pode ser feita por qualquer um, no caso de situações onde não há um manejo específico da morte, destacando-se o predomínio da pessoalidade. Conclusão: apesar da formação em psicologia não conter uma especificidade no que diz respeito à morte, o que impõe ao profissional dificuldades operativas nas situações de morte iminente, essas dificuldades podem ser minimizadas desde que o psicólogo tenha bem definido - para si e para a instituição na qual atua - qual é a sua função, assim, não perdendo a dimensão profissional. Além disso, reforça-se a importância do psicólogo realizar sua terapia pessoal, perante um fazer marcadamente convocador da pessoalidade.
\end{abstract}

Palavras-chave: Psicologia Clínica. Saúde Pública. Morte. Psicologia em Saúde.

\section{Introdução}

A morte é um fenômeno complexo e de implicações profundas, sobre o qual não há uma formulação estabelecida que indique uma definição única, isto é, quando falamos de morte não necessariamente falamos todos da mesma "coisa". Por exemplo, um jovem submetido às drogas está vivo ou morto? Biologicamente vivo é suficiente à qualificação do que seja estar vivo?
1. Psicóloga. Graduada pela Universidade Federal de Santa Maria no ano de 2008.

2. Docente. Departamento de Psicologia. Centro de Ciências Sociais e Humanas - Universidade Federal de Santa Maria (UFSM).
Correspondência: Cláudia Maria de Sousa Palma Universidade Federal de Santa Maria. Centro de Ciências Sociais e Humanas. Departamento de Psicologia Rua Floriano Peixoto, 1750 97105-900. Santa Maria, RS, Brasil. Email: claupalma@uol.com.br

Artigo recebido em 13/08/2008 Aprovado em 11/09/2009 
Nessa via, as discussões sobre eutanásia apontam para a multiplicidade de fatores que intervêm na própria definição de morte biológica. Com efeito, a abordagem à morte parece-nos não poder desconsiderar, também, aspectos culturais e individuais, ${ }^{1}$ além das evidências físicas, configuração que limita o estabelecimento de uma definição única e, portanto, generalista.

Percorrendo a historicidade do manejo cultural e técnico da morte física, notamos que, antigamente, ela era abordada com mais clareza em seu critério biológico: morria-se por afecções - hoje facilmente tratadas - o que impunha uma significativa frequência de óbitos com sinais evidentes que os indicavam e, também, um ritual costumeiro, numa tentativa de simbolização que atingia a efetividade esperada, isto é, a cultura favorecia a inserção da ruptura com a vida. ${ }^{2-7}$

Entretanto, com o desenvolvimento da tecnologia, gradativamente, o homem passou a adotar comportamentos que buscavam o distanciar dos sentimentos de dor e perda que a morte ocasionava, ${ }^{2,5,6}$ ou seja, a cultura não mais favorecia a organização dos efeitos da morte nos que permaneciam vivos.

É assim que a modernidade, com a valorização da autonomia subjetiva e a necessidade de se construir uma trajetória a ser vivida, promovendo um franco desenvolvimento tecnológico na área da saúde, ${ }^{6}$ leva a um distanciamento dos efeitos produzidos pelo fenômeno da morte. Nesse contexto, o campo clínico médico define a morte de um ponto de vista biológico como um processo natural, pertinente à vida do ser humano, portanto, universal, inevitável e reconhecível pelos sinais do corpo. Em contrapartida, para a psicanálise, a morte não é prontamente reconhecível. ${ }^{8,9}$ Ao contrário, ela é desconhecida, não estando inscrita em nosso inconsciente, ou seja, não há simbolização do fenômeno, fato que retira do homem a possibilidade de controle sobre o evento.

Entretanto, a não inscrição da morte na subjetividade não retira a ação de sua iminência. Na perspectiva psicanalítica, a busca por uma condição de ausência excitatória é inerente ao aparelho psíquico, ou seja, nele estão presentes tendências primitivas altamente pulsionais, atribuídas ao recalcado inconsciente, as quais buscam restaurar um estado anterior à própria constituição do sujeito desejante $\left.{ }^{*}\right)$, onde a excitação é mínima. ${ }^{9}$
Tais tendências foram nomeadas, por Freud (1920), pulsão de morte, e operam no aparelho psíquico no circuito paralelo ao circuito do discurso (simbólico), fato que impõe a necessidade de outro manejo clínico, que não a rememoração de sentido. Assim, sugerimos pensar a operação do fenômeno da morte como um reflexo do que se dá em nossa sociedade e, também, na subjetividade.

A morte física, nas instituições de saúde, se apresenta como um evento distanciado, negado, silenciado e esvaziado de significado, na medida em que se põe contra o ideal de cura - controle, eficiência ficando, o morrer, cada vez mais triste e solitário, sem palavras, distanciado da sociedade e da família. Este fato aponta para o modo como a própria pulsão de morte incide em nossa subjetividade, isto é, à margem, silenciosa de palavras, solitária.

Partindo desse cenário, qual seja, a configuração assumida pela morte nas instituições de saúde e, também, a importância da atuação do psicólogo nesses locais - como membro da equipe interdisciplinar buscamos, nesse artigo, através de entrevistas realizadas com psicólogos que atuam na rede pública de Santa Maria, levantar dados a respeito do manejo adotado por esses profissionais em situações de morte física iminente, bem como a postura adotada pelo profissional diante de questões relativas à morte no que se refere à sua individualidade.

No que tange à operatividade com a iminência e as consequências da morte, atualmente, no âmbito público, o local delegado às mortes físicas são os quartos de isolamento ou até mesmo as Unidades de Terapia Intensiva (UTIs) das instituições de saúde. É nesse cenário que atua o profissional da saúde, nos quais podemos incluir o psicólogo, defrontando-se diariamente com questões de dor e sofrimento frente à morte.

Dentro desse contexto, o profissional identifica-se com o mal-estar universal que a morte suscita. É formado para curar e, no entanto, por vezes, sentese perdido sobre como lidar com o fim da vida e a aproximação da morte. Assim, esse contato intenso e frequente com a dor, o sofrimento e o morrer, tornase um fator estressante ao profissional da saúde ${ }^{10}$ que, muitas vezes, perde a dimensão subjetiva da dor e do sofrimento, os quais podem re-significar a morte.

Ainda dentro dessa perspectiva de mal-estar gerada no profissional da saúde pelo contato com a

\footnotetext{
* Àquele que, a partir do simbólico, busca operar com as tendências primitivas em sentido contrário à força de manutenção do estado anterior de reduzida excitação.
} 
iminência de morte, outro fator que exerce elevada influência é a organização do trabalho na instituição hospitalar, um modelo alienado, no qual se segue a vontade do outro, hierarquicamente superior, e se privilegia a disciplina e o controle, não somente dos pacientes, mas também dos profissionais que nele atuam. A organização do trabalho nessas instituições e as relações estabelecidas entre os profissionais que nelas atuam se dão conforme o lugar ocupado pelo profissional na hierarquia com base no saber, a qual divide os homens e as tarefas, além dos privilégios, dos quais desfrutam aqueles que se encontram no topo da pirâmide hierárquica. Significa dizer que, conforme o trabalhador estiver mais abaixo nela, maior é seu contato com os pacientes enfermos, com situações de dor e de morte e, maior, também, o despreparo e a submissão à hierarquia. ${ }^{10}$

Consequentemente, tal configuração interfere na maneira com que esses profissionais irão lidar com a morte, já que são vários profissionais e diversos saberes envolvidos nesse trabalho interdisciplinar, onde, não raras vezes, os saberes se sobrepõem e acabam gerando conflitos e tensões entre os membros da equipe.

Como desdobramento corrente aparece, também, a adoção de mecanismos de defesa frente às dificuldades de trabalho e à angústia despertada pela iminência de morte. Tal cenário diz respeito a uma perspectiva importante do trabalho do psicólogo, no sentido de que, muitas vezes, faz-se necessária a intervenção na relação entre equipe, pacientes e familiares, visando o estabelecimento de uma boa comunicação entre os envolvidos.

Portanto, considerando a perspectiva pulsional convocada pela morte física nos pacientes e nos profissionais da saúde, e a necessidade do psicólogo operar com os fenômenos subjetivos vinculados à morte física, esse trabalho pretende investigar e analisar o fazer do psicólogo em instituições públicas de saúde, em Santa Maria, no que se refere especificamente ao manejo psíquico ofertado ao paciente e, secundariamente, aos seus familiares, frente à iminência de morte física.

\section{Materials e Métodos}

Inicialmente, o projeto passou pela análise e aprovação do Comitê de Ética e Pesquisa (CEP) da Universidade Federal de Santa Maria (UFSM), seguindo a resolução 196/96 do Conselho Nacional de Saúde.
Posteriormente, foi realizado levantamento sobre o número de psicólogos que atuam na rede pública de Santa Maria juntamente às instituições, mediante requerimento de informações referentes aos locais de trabalho e aos psicólogos que neles atuam. Dessa forma, constituiu-se um grupo de dezesseis psicólogos, ou seja, todos os psicólogos da área de saúde pública de Santa Maria, dentre os quais doze atuam na rede municipal de saúde - desenvolvendo atividades nos Centros de Atenção Psicossocial (CAPs), Ambulatórios de saúde mental e Redução de Danos e quatro fazem parte do quadro de profissionais que trabalham no hospital universitário.

Estes profissionais atuam, predominantemente, no nível ambulatorial, com uma modalidade de intervenção que tanto pode ser individual ou grupal, recebendo pacientes de todas as faixas etárias - idosos, adultos, adolescentes e crianças. Portanto, o critério estabelecido para a seleção dos sujeitos dessa pesquisa circunscreveu-se à condição de ser um psicólogo atuante na rede pública de saúde de Santa Maria.

Entretanto, devido ao número limitado de profissionais nessa condição e, também, ao objetivo da pesquisa, fatores como idade, sexo, estado civil, tempo de serviço não foram utilizados como variáveis para a seleção dos entrevistados.

A partir daí, optamos pela realização de entrevistas semi-estruturadas ${ }^{(*)}$ e individuais, caracterizadas pelo estabelecimento de eixos norteadores de forma a contemplar os objetivos dessa pesquisa, já que essa técnica proporciona ao entrevistado uma livre descrição de suas vivências e, também, permite ao entrevistador esclarecer possíveis lacunas no campo de entrevista.

Foram realizadas doze entrevistas - já que quatro psicólogos optaram em não participar da pesquisa - com o objetivo de levantar dados a respeito do manejo adotado pelo psicólogo em situações de morte física iminente, bem como a postura adotada pelo profissional diante de questões relativas à morte no que se refere à sua individualidade. As entrevistas com cada participante tiveram duração de aproximadamente uma hora, e a maioria delas foi gravada a fim de auxiliar o trabalho do pesquisador na captação de um maior número de dados, entretanto, duas delas não foram gravadas por opção dos participantes.

Posteriormente, todas as entrevistas foram transcritas na íntegra, e, em seguida, foram grifados

${ }^{*}$ Roteiro em anexo 
alguns aspectos importantes do discurso dos profissionais, levando em conta nosso objetivo. A partir daí, utilizando um referencial teórico psicanalítico para análise dos dados, foram estabelecidas algumas categorias a posteriori, ou seja, depois de lida a entrevista e destacados os aspectos recorrentes e indicadores do manejo clínico na perspectiva individual. Categorias que pudessem articular uma perspectiva grupal, no que tange as características do profissional; as condições de trabalho; a morte na visão do psicólogo e ao manejo da morte.

Entretanto, no presente artigo, levando em conta a extensão que nos é permitida, selecionamos para discussão as seguintes categorias: condições de trabalho; a morte na visão do psicólogo e o manejo da morte e apresentamos os trechos mais recorrentes no discurso dos psicólogos, a fim de mostrar os procedimentos adotados na pesquisa e apresentar os resultados que acreditamos serem relevantes ao campo de estudo em questão.

\section{Resultados: apresentação e discussão}

No que se refere à categoria: "condições de trabalho do psicólogo nas instituições de saúde", um aspecto fundamental incidente, diz respeito às relações de poder e disciplina, expressas comumente, no linguajar técnico adotado pela equipe, cheio de "jargões", e pela hierarquia rígida e verticalizada instituída na base do saber. ${ }^{10}$ Assim, um fator agravante, nas condições de trabalho, apontado pelos psicólogos entrevistados tangencia a relação do psicólogo com a equipe de profissionais, na qual estão envolvidos diversos saberes e discursos, surgindo questões hierárquicas, bem como variações na visão que os profissionais apresentam do paciente, nos quais alguns saberes se sobrepõem aos outros, caracterizando fato gerador de tensões e que, consequentemente, se reflete no manejo adotado para se lidar com a situação de morte. Como podemos verificar no seguinte trecho:

"(...) tem uma questão muito delicada de você estar lidando dentro de um hospital, principalmente de trabalhar como psicólogo (...) é complicado porque dentro do hospital aqui ainda tem uma estrutura muito vertical. Você tem o médico como uma figura bastante distante e centralizadora e de muita autoridade, muito poder, âhm, numa relação vertical com essa equipe (...) é uma maneira muito diferente que psicólogos e psiquiatras, principalmente psiquiatras mais tradicionais, enxergam o paciente que eles atendem. Então, isso gera uma série de tensões em que é complicado lidar com isso." (entrevista 10)

Outro atributo apontado, ainda nessa categoria, é a perspectiva curativa da saúde, como podemos conferir no seguinte trecho:

"A gente tem muito pouco trabalho com a comunidade (...) Se pensa o psicólogo para a saúde mental em segundo plano. Primeiro vem o psiquiatra, a medicina e depois a psicologia. Eu acho que a gente, dificilmente, trabalha isso como saúde. A gente trabalha, em geral, em curar doenças." (entrevista 5)

A perspectiva curativa pode influenciar no trabalho do psicólogo, ${ }^{6,11}$ ou seja, na percepção que esse profissional tem do trabalho, os sentimentos suscitados, bem como na sua motivação, já que, em termos de suas exigências em relação ao trabalho do psicólogo, ela acaba priorizando os números ao invés da qualidade do atendimento:

"Às vezes, a gente acaba entrando em conflito, sabe, com diretor, com chefe, pra poder manter uma excelência. Todo mundo te cobrando números e tu mantendo o teu atendimento de $40 \mathrm{mi}$ nutos." (entrevista 9)

Já na categoria que se refere "à morte na visão do psicólogo", na representação que os entrevistados possuem ela é encarada como finitude, a inexistência, algo natural e inevitável, não desejável, porém, real, ou seja, a morte é concebida pelos psicólogos entrevistados numa perspectiva biológica. Desta maneira, a morte, segundo alguns autores, à medida que se aproxima do profissional, faz com que ele se defronte com suas limitações pessoais e teóricas, ${ }^{6,11,12}$ mobilizando a polaridade onipotência-impotência.

"A morte é o fim da vida e claro que eu não quero morrer, e claro que eu não quero que as pessoas que eu tenho carinho morram, mas eu não acho que existe vida após a morte. Ãhm, não tem nada que me conforme (...) Acho que é uma merda quando morre alguém que tu ama (...) Mas também acho que vai chegar uma hora que a gente vai ter que reagir (...)" (entrevista 4)

"Acho que é uma das coisas mais complicadas (...) Eu penso a morte como algo natural. Mas não algo desejável, néh. Eu tento lidar com isso." (entrevista 5) 
Dessa forma, o profissional, diante do desamparo técnico suscitado pela situação de morte, acaba utilizando certos recursos defensivos na tentativa de proteger-se da invasão ameaçadora desses sentimentos. Há várias modalidades de defesa desenvolvidas pelos profissionais da saúde, ${ }^{10}$ nos quais podemos incluir os psicólogos. O recurso mais simples e adotado com maior frequência é a negação, na qual se afirma que todos os pacientes são iguais para o profissional ou pela exacerbação da interpretação e/ou no silêncio e na omissão de relatos sobre suas reações emocionais, ${ }^{12}$ através do qual o profissional se mantém afastado de sua fragilidade e com os sentimentos controlados, evitando identificações. Portanto, através da adoção dos mecanismos de defesa é possível a redução do peso da responsabilidade e da ansiedade gerada pela morte física. Nas entrevistas, esses mecanismos estão exemplificados pelo distanciar-se da questão para falar sobre ela e o colocar-se diante do assunto pela via do universal, reproduzindo discursos aprendidos, como nos seguintes trechos:

"Acho que na adolescência, na fase da infância deve ser doloroso perder a mãe ou o pai (...) E na fase adulta, eu acho que o adulto, ele tem uma condição, pela maturidade (...) de suportar mais (...) ela te dá mais recursos pra lidar com a dor (...) É doloroso. Porque o que acontece na fase adulta, quanto mais velha você vai ficando, vai perdendo os familiares (...) Quem vai gostar da questão da morte (...) Há necessidade de você ir se preparando e que é uma carga, assim, pesada, mas que você tem que aprender a lidar." (entrevista 6)

"A morte ainda é um preconceito. Em geral, a negamos. Tem uma frase do Freud, que fala que quem está preparado para a morte está mais preparado para a vida. Não estamos preparados, em geral (...) A morte faz parte da vida." (entrevista 7)

Já no que se refere à categoria "o manejo clínico da morte", podemos notar que esta é abordada pelo psicólogo como uma perda que faz parte da vida do homem, tratada de acordo com "aquilo que o paciente fala" (sic) ao terapeuta. Assim, parece haver uma teoria (referência a Freud) que dirige os atendimentos ao particular (referência à fala do paciente), mas não se adota um recurso teórico-técnico específico para essa procedência singular, restringindo-se as intervenções às possibilidades de sentido a um universal da existência - morte vista como uma perda que compõe o humano.

Com efeito, verifica-se um fazer que não se estabelece pela via da experiência singular, na qual a abordagem à morte deve-se assentar, à medida que essa escapa a qualquer técnica universalizante, não havendo regras fixas e nem procedimentos gerais. ${ }^{5,12,13}$ Em nosso estudo, percebemos que o cuidado adotado de forma geral nesse tipo de atendimento, deu-se no sentido de uma escuta sensível àquilo que o paciente verbalizava ao psicólogo, respeitando-se o tempo de elaboração pelo paciente frente à morte.

"Nesses casos, em geral, isso pede uma abordagem mais voltada para o acolhimento, que para uma intervenção mais ativa, da parte do psicólogo. Em geral, um momento de você ser mais maternal, vamos dizer assim, ser mais continente (...) eu acho que tem que se dar mais tempo pro paciente, acho que a gente tem que ser prioritariamente acolhedor e num segundo momento, numa segunda sessão, terceira, sei lá, ai sim a gente avaliar se isso tem outras significações, pode ser uma desculpa realmente, se é um luto que vai se desenvolver normalmente ou não (...)" (entrevista 10)

Portanto, levando-se em conta que morte é tratada como uma perda que faz parte da vida do homem - sentido biológico predominantemente - a partir "daquilo que o paciente fala" ao terapeuta, pode-se notar que há uma contradição entre a forma como os entrevistados concebem a morte e o modo como a abordam no tratamento, ou seja, esses psicólogos concebem a morte pela via do universal (processo biológico, natural e inevitável), entretanto, propõem uma modalidade de intervenção na qual a iminência da morte é tratada como algo singular (escuta a fala própria do entrevistado).

Logo, diante do singular, quando se utilizam de procedimentos padrões e/ou universais, propõem uma terapêutica equivocada, ineficaz, dificultando o tratamento deste tipo de situação onde, também, há uma maior convocação da pessoalidade - conjunto de crenças e valores - do profissional.

"Se tu for ver que a nossa atuação clínica vai de acordo com a necessidade que o paciente tá mostrando (...) eu busco pautar a minha intervenção em função da necessidade da pessoa (...) nesse sentido eu não vejo diferença no atendimento. Se a necessidade é trabalhar a questão da morte e a pessoa já ta antecipando a elaboração do luto 
e é esse o material que ele quer trabalhar, bom, é isso que eu vou trabalhar (...) Então, a morte ela não é uma questão que é trazida por mim, psicóloga (...) Não tem uma conduta imposta (...) Então, não tenho assim óh: o procedimento padrão." (entrevista 11)

"Isso é muito chocante pra gente como profissional da saúde, sempre voltado à vida, a preservar a vida, a elevar a qualidade de vida, e, às vezes, a gente tende até a concordar. É um dilema grande esse da tua obrigação de preservar a vida e por outro lado, às vezes, tu não poder fazer a pessoa... eu não tenho esse direito, e de você até, num momento de maior empatia, de você pensar: 'Então, se fosse eu, eu não sei se eu não faria a mesma coisa numa situação dessas'." (entrevista 10)

O que deve diferenciar, no nosso entendimento, o trabalho do psicólogo dos outros profissionais é o seu oferecimento à escuta de outra cena, que está além da concretude da narrativa, já que, independente da fragilidade física ${ }^{4}$ que pode acometer um sujeito próximo à morte, se há o interesse em tratar do mal-estar, há a possibilidade de se falar para além dos sentidos universais e, assim, re-contar a dor experimentada.

Assim, o psicólogo que atua junto às pacientes na iminência de morte, não pode prescindir de questionar o significado do sofrimento. ${ }^{12}$ Segundo Torres e Guedes (1982), ele vai ajudar o paciente a adquirir uma sobrevivência significante e uma morte apropriada, pois os pacientes terminais têm uma ilimitada necessidade de se exprimir para alguém, refazendo o percurso trilhado em sua vida.

Além disso, ainda na categoria "o manejo clínico da morte", podemos perceber que o conhecimento básico da graduação em psicologia não os prepara para atuar nas situações de morte, ${ }^{4,6,11-15}$ como podemos perceber no seguinte trecho, no qual o profissional se vê obrigado a agir pelo bom senso e corre o risco de uma atuação não embasada teoricamente, sem especificidade, que poderia ser feita por qualquer um.

"Eu tenho livros, eu li livros sobre a morte (...) Juntei muitos livros na época e comecei a ler, pra começar a entender. Mas eu acho assim óh: uma coisa, que é tu agir muito com o coração, que nessa hora, assim óh, tu tem que ter uma dedicação total, não é mais empatia, não é tão... (...) Eu acho que é uma coisa espiritual... não solicita mo- dificação, não aceita modificação algumas coisas são muito espiritual. Eu acreditava assim óh, isso tu vai ver com o tempo, que o paciente, ele custa muito a se despegar da vida. Não é só difícil nascer. É difícil morrer. (...) Então, às vezes, eu tenho que fazer até o papel daquela pessoa que não tá ali no momento." (entrevista 8)

Como consequência, o desconhecimento do profissional em relação ao assunto é perigoso quando se resolve criar um fazer, digamos pessoal, como saída à angústia que o desconhecido causa. Assim, aparecem intervenções voltadas mais para o espiritual e ao social do que para o psicológico. Essa atitude desorientada, não referenciada teoricamente, pode depreciar pacientes e familiares quando extrai, por exemplo, o ritual fúnebre - intervenção de um dos entrevistados - com base em percepções pessoais do profissional e externas ao sujeito em questão:

"... 'Só que agora a gente sabe que teu tempo acabou aqui na terra...'...

A gente aconselhava a não velar na cozinha, pra não ficar marcada a família. Tentava desmistificar aquela história da morte." (entrevista 8)

Ainda no que se refere à categoria, "o manejo clínico da morte", este é considerado por alguns profissionais um trabalho desgastante, uma vez que o psicólogo também tem que lidar com uma perda. O trabalho clínico nas situações de iminência de morte é um evento considerado estressante, ${ }^{14}$ principalmente quando o psicólogo não está preparado para lidar com essa situação, já que ela suscita sentimentos muito fortes e contraditórios no profissional, ${ }^{10}$ confrontando-o com sua finitude e suas limitações técnicas. ${ }^{6}$

"A gente, enfim, tem que lidar com uma perda também (...) Acho que seria um trabalho basicamente de escuta. Porque, repito, assim, não tem um único manejo, as pessoas são diferentes (...) Acho que não é nada fácil (...) Porque é um trabalho, assim, muito desgastante. Eu não ia, por exemplo, conseguir lidar com isso todos os dias, com essa situação ou lidar com várias pessoas na mesma situação no mesmo dia. Eu teria que fazer alguma coisa para elaborar isso também (...) Acho que dai ou tem que arranjar um outro tipo de atividade profissional, que de alguma maneira te faça compensar isso, ou tu cria um mecanismo de defesa, que nem o médico." (entrevista 4) 
Deste modo, a soma desses fatores, anteriormente discutidos, também nos remete ao risco do profissional apresentar-se de forma onipotente, o que lhe faz experimentar a impotência nos casos em que a intervenção clínica é impossível, como por exemplo, quando do suicídio planejado pelo paciente:

"(...) é muito chocante a gente ver uma pessoa que fala da morte, do suicídio, como a solução para os seus problemas e te traz isso como uma decisão ponderada e não é um momento de desespero, não é um impulso, é uma decisão. Isso é muito chocante pra gente como profissional da saúde, sempre voltado à vida, a preservar a vida, a elevar a qualidade de vida, $e$, às vezes, a gente tende até a concordar. É um dilema grande esse da tua obrigação de preservar a vida e por outro lado, às vezes, tu não poder fazer a pessoa... eu não tenho esse direito, e de você até, num momento de maior empatia, de você pensar: 'Então tá, se fosse eu, eu não sei se eu não faria a mesma coisa numa situação dessas" (entrevista 10)

Agir guiado por um pensamento onipotente gera uma ação onipotente ${ }^{17}$ e, na medida da impossibilidade de efetividade desta, aparecem à cena a frustração, a impotência e a busca por balizas universais de sentido para a condução do tratamento.

\section{Conclusão}

Levando em conta o manejo clínico dos profissionais entrevistados frente às situações de iminência de morte, verificamos as dificuldades operativas destes para com os pacientes, à medida que, inseridos num contexto de saúde e sem o preparo teórico-clínico-pessoal necessário, acabam numa abordagem médica com intenção psicológica. Esta configuração pode explicar a angústia e a utilização de recursos defensivos na condução clínica.

Outro fato verificado nas entrevistas, e que favorece a configuração examinada anteriormente de angústia perante as situações de morte iminente, é o fato dos profissionais da saúde, principalmente os psicólogos - os quais são foco de nosso interesse neste trabalho - saírem da universidade com uma formação predominantemente generalista e com base no modelo privado de intervenção, que não os prepara para atuação, no sentido de contemplar as peculiaridades da demanda da saúde pública e, especificamente, em relação à temática da morte.
Além disso, são apontadas nas entrevistas, como condições agravantes, a condução clínica, as questões de organização do trabalho, relacionadas à elevada verticalização hierárquica com base nos diferentes saberes, em situações nas quais esses diferentes saberes e discursos se sobrepõem, gerando controvérsias entre os membros da equipe e dificultando a comunicação entre eles, funcionando, tal situação, como um entrave ao trabalho em equipe interdisciplinar. Nesse caso, esse recurso - a equipe - ao invés de somar, acaba por subtrair no manejo com o paciente.

Naquilo que tange à atuação do psicólogo na situação de iminência da morte de um paciente, em contraponto com o seu posicionamento pessoal sobre o assunto, aparece uma contradição relacionada à forma com que os psicólogos concebem a morte e sua respectiva atuação profissional. Eles, em sua maioria, concebem a morte segundo os sentidos produzidos pela ciência médica e pela cultura; entretanto apontam para um fazer em que ela é trabalhada como uma perda particular e, nesse sentido, revelam que não podem adotar a especificidade necessária à abordagem do particular, já que não contemplam para si mesmos tal particularidade.

Seguindo ainda essa via de compreensão, qual seja a busca de uma escuta singularizada numa situação concebida genericamente, como escutar a perda relatada pelo paciente como algo particular, uma dor singular, quando se concebe a morte pelo universal, isto é, algo da ordem do inevitável e comum a todos os homens?

Uma consequência importante é que tal contexto traz uma maior convocação à pessoalidade do psicólogo - no caso de não haver o preparo profissional necessário - e, com efeito, sua concepção de morte acaba se reproduzindo no atendimento ao paciente, influenciando na escuta daquilo que o paciente apresenta, dificultando a direção clínica que visa à construção singular de sentido.

Logo, nas situações de iminência de morte, independentemente da técnica e modalidade de intervenção, o psicólogo não pode perder a dimensão profissional, no sentido da necessidade da máxima suspensão possível de sua pessoalidade para poder manter a operatividade com o outro - paciente.

Portanto, podemos inferir, de acordo com os dados levantados nas entrevistas e de acordo com o referencial teórico adotado, que é importante ao psicólogo saber, primeiramente, qual a sua função, es- 
sencialmente, de um profissional que trabalha de forma a proporcionar um espaço de elaboração do sofrimento psíquico do sujeito, pela escuta sensível e acolhimento de suas angústias, o que, consequentemente, pode proporcionar maior adesão do paciente à própria historicidade.

Destacamos, também, com nosso estudo, a importância da delimitação de um lugar para o psicólogo na equipe. É fundamental que o psicólogo compreenda o seu papel enquanto mediador entre a equipe, pacientes e familiares, de forma a garantir uma melhor e mais efetiva comunicação entre eles. Além disso, ocupa um papel importante dentro da equipe de saúde, agindo como um facilitador das relações entre seus membros, através da busca do desenvolvimento de uma linguagem comum e de conhecimentos recíprocos dentro da própria equipe, que são necessários à interação conjunta. $^{8}$

Dessa forma, conhecendo qual a sua função na instituição e dentro da equipe de saúde, o psicólogo saberá qual o papel esperado que ele cumpra e quando confrontado com as questões relativas à morte, tal saber-fazer poderá auxiliá-lo para não cair na "armadilha" de realizar um trabalho que pode ser feito por qualquer um, ou até mesmo gerando intervenções que ao invés de permitirem a elaboração, prejudiquem. Esse conhecimento teórico e técnico, sobretudo, deve, em parte, ser adquirido durante a graduação, sendo fundamental ao embasamento da atuação do psicólogo.

Com efeito, é de capital importância a questão da análise pessoal do profissional, a qual the possibilitará trabalhar com sua subjetividade, permitindo-lhe diferenciar o que é seu e o que é do seu paciente, não impondo, assim, ao paciente, algo que compõe a pessoalidade do profissional. Tal prática, assim configurada, parece estabelecer maior clareza à intervenção, já que o manejo na situação de morte, a partir de sua incidência na subjetividade, deve acontecer de acordo com a demanda do paciente e as possibilidades do contexto, pois, não há regras fixas ou procedimentos específicos que sejam aplicados a toda e qualquer situação.

Ainda nessa perspectiva, o paciente é quem fala ao psicólogo sobre aquilo que o atormenta e não é o psicólogo quem irá estabelecer os conteúdos a serem abordados. Entretanto, se é fato que o psicólogo não dirige o paciente, isso não quer dizer que não dirija o tratamento, de forma que o paciente consiga significar suas vivências fundantes. Portanto, o trabalho dos psicólogos é diferente daquele realizado por outros profissionais, como, por exemplo, os médicos, que apresentam uma intervenção mais pontual, diretiva ao paciente, menos frequente, com acesso à concretude do problema, intervindo de forma diferenciada, posto que no concreto do corpo.

Para melhor ilustrar essa diferença, tomemos como exemplo a questão da dor, que é uma experiência pessoal e subjetiva inerente à existência humana. Nesse contexto a atitude do médico é mais pontual, objetiva e necessária para acabar com a dor física. Já na perspectiva "psi", a dor subjetiva é um importante indicador de que algo está errado, apontando para onde deve se dirigir o tratamento.

Assim, tomando a referência do mal-estar, em contraponto com essa perspectiva de retirada da dor, o psicólogo realiza um acompanhamento mais frequente e deve conseguir sustentar a escuta da dor subjetiva do paciente, acolhê-la para além da concretude de sua descrição, ofertando a construção de um sentido atribuído pelo paciente que lhe permita um fazer contra o mal-estar. Com isso, poderá sair da posição de uma vivência passiva e/ou contaminada da dor e assumir uma participação mais ativa no seu tratamento.

Além disso, ainda sob a perspectiva da escuta da dor realizada pelo psicólogo, o sentido desta para o paciente não está dado "a priori", considerando a particularidade de cada um. Um exemplo de sentido que esta possa adquirir para o paciente pode se assentar numa resposta à própria condição da hospitalização, pois nos hospitais, pelas características próprias da instituição de homogeneizar os pacientes, como forma de garantir o controle e a total assepsia, muitas vezes, o paciente se utiliza dessa dor subjetiva como forma de se singularizar e se diferenciar dos demais pacientes.

Enfim, através deste estudo buscamos qualificar a prática do psicólogo que atua na saúde pública de Santa Maria diante da iminência de morte de seu paciente, destacando os benefícios da intervenção psíquica para este e para a equipe interdisciplinar. Nossos dados reforçam a importância em adotar-se uma prática embasada teoricamente, específica, aliada à efetivação da análise pessoal do profissional, de forma que este possa superar as "armadilhas" geradas pelo desconhecimento, tanto da teoria quanto de si próprio, bem como do inusitado que compõem a particularidade de cada situação vivenciada e o intangível da morte. 


\begin{abstract}
Study design: It is a qualitative research. Objective: To qualify the practice of the psychologist, that is, how they behave and work facing questions concerning death in the institutional context. Methods: Initially, it was carried out a survey on the number of psychologists who work in the health public system in Santa Maria establishing a sample of twelve professionals. Later, semi-structured and individual one-hour long interviews were conducted. The recorded interviews were transcribed and then read individually; highlighting the parts of speech that showed the way the psychologist develops his work and from the recurrence, some categories of analysis were elaborated, trying to articulate a group's view. The theoretical-psychoanalytic focus was used for the data analysis. Results: The results showed contradictions between the performance and positioning of the psychologist on the verge of death of a patient, with the predominance of individual characteristics in their act. Thus we could realize the danger of adopting a practice anyone can do, in the case of situations where there is not a specific handling, with stress in the dominance of individual characteristics. Conclusion: Although training in psychology does not have any specificity with regard to death, which imposes the professional some professional difficulties in situations of imminent death, these difficulties can be minimized since the psychologist has clearly defined to himself and to the institution in which he works - what is his function, thus without missing his professional dimension. Moreover, it is reinforced the importance of the psychologist having his own personal therapy to be able to deal with those matters which demand his individual characteristics.
\end{abstract}

Keywords: Psychology, Clinical . Public Health. Death. Health Psychology.

\section{Referências Bibliográficas}

1. Coppe AAF. Morte: uma questão em vida. Cad Psicol. 1995; 3: 37-9.

2. Ariès $P$. História da morte no ocidente: Da idade média aos nossos dias. Rio de Janeiro: Francisco Alves; 1977: 17-28 e 53-62.

3. Kastenbaum R, Aisenberg R. Psicologia da morte. Edição Concisa. São Paulo: Pioneira; 1983.

4. Lastiri SMAF. Três olhares sobre a morte. Psicol Hosp. (São Paulo). 2003; 1: 28-34.

5. Kovács MJ. Morte e desenvolvimento humano. 4a ed. São Paulo: Casa do Psicólogo; 2002.

6. Kovács MJ. Educação para morte. Psicol. ciênc. prof. Set 2005; 25 (3). [acesso em 31 de março 2007]. Disponível em: $<$ http://pepsic.bvs-psi.org.br/scielo.php?script=sci_arttext \&pid=s141498932005000300012\&lng=pt\&nrm=iso>

7. Chiattone HB. A criança doente e a morte. In: Angerami-Camon VA. (Org.) E a psicologia entrou no hospital... São Paulo: Pioneira; 2004: 73-101.

8. Freud S. Reflexões para os tempos de guerra e morte. (1915) In: Edição Standard Brasileira das Obras Completas de Sigmund Freud. Vol. 14. Rio de Janeiro: Imago; 1996. 283-312.

9. Freud S. Além do princípio do prazer. (1920) In: Edição Standard Brasileira das Obras Completas de Sigmund Freud. Vol. 1. Rio de Janeiro: Imago; 1996: 13-75.
10. Pitta AMF. Hospital: dor e morte como ofício. 4ae ed. São Paulo: Hucitec; 1999.

11. Kovács MJ. Pensando a morte e a formação de profissionais de saúde. $2^{\text {a }}$ ed. In: Roosevelt MS. \& Cassola (Coord.) Da morte: estudos brasileiros. Campinas: Papirus Editora; 1991: 79-103.

12. Torres WC, Guedes WG. O psicólogo e a terminalidade. Arq Bras Psicol. 1987; 39: 29-38.

13. Silva MHF. Lidando com a morte: a especificidade do sofrimento do profissional da saúde no contexto hospitalar. Psicol Argum. 1995: 13: 95-120.

14. Combinato DS, Queiroz MS. Morte: uma visão psicossocial. Estud Psicol. (Natal). 2006; 11 (2): 209-16.

15. Torres WC, Guedes WG, Torres RC. (Coord.) A psicologia e a morte. $1^{a}$ ed. Rio de Janeiro: Editora da Fundação Getúlio Vargas; 1983.

16. Schlindwein R. Aspectos psicológicos da terminalidade, do luto e do morrer. Rev Virtus. 2001; 1: 19-30.

17. Franco MHP. Cuidados paliativos e o luto no contexto hospitalar. Mundo saúde. 2003; 27:182-4.

18. Romano BW. Princípios para prática da psicologia clínica em hospitais. São Paulo: Casa do Psicólogo; 1999. 10-100. 


\section{Anexo}

\section{Roteiro das entrevistas}

\section{Temáticas a serem abordadas pela Entrevista:}

\section{A) O Psicólogo e a Instituição de Saúde:}

- Como o profissional se aproximou da área da saúde.

- Como o profissional se decidiu pelo trabalho com pacientes em sofrimento e morte.

- Qual a opinião dele sobre a inserção do Psicólogo na Instituição de Saúde.

B) O Psicólogo e o Manejo Clínico da Morte:

- Como são os procedimentos, se há alguma especificidade na condução clínica.

- Quais as dificuldades para o trabalho.

- Se há diferença no manejo da morte no caso de suicídio.

- Se os conhecimentos adquiridos através da graduação ajudam na Clínica.

C) O Psicólogo:

- O que ele pensa sobre a morte.

- Quais suas dificuldades pessoais. 